\title{
Introduction Vol. 2 Issue 1 International Journal of Community Well-Being
}

\author{
Rhonda Phillips ${ }^{1} \cdot$ Seung Jong Lee ${ }^{2}$ \\ Published online: 29 April 2019 \\ (C) Springer Nature Switzerland AG 2019
}

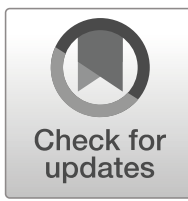

It is our pleasure to introduce the second volume of the International Journal of Community Well-Being. This is the first journal to focus exclusively on the topic of community well-being that is also intentionally inclusive of diverse perspectives whether it be theory, discipline, practice, or geography. As John Haworth noted in Vol. 1 Issue 2, well-being is by definition "something we do together" and thus community well-being must be understood as a multidisciplinary topic. In addition to the longstanding interest in this topic from community development, geography, urban and regional planning, economic development, public administration, regional studies, sociology, community learning and education, psychology and health, we are excited to see interests emerging from new fields.

The articles in the first and second issue of Volume 1 reflect this growing interest across the various disciplines and speak to the international aspect of this journal. The articles examined a wide variety of topics, such as well-being, happiness, sustainable development, urban development, and neighborhood. Together, they show how community well-being is a multifaceted concept.

We expect the journal to continue to serve as a space for dialogue and sharing of ideas and practices from around the globe. As we noted in the last issue's introduction, community well-being is a topic with many definitions. While this leads to much anxiety in traditional academia, we think the wrestling with different definitions, practices, and ideas and the periodic reflections on these are invaluable. Thus, we look forward to seeing more articles that explore how different ideas of well-being relate (or do not relate) to each other and how different communities practice community wellbeing. The journal welcomes practitioner essays and theoretical debates as well as comparative research to build interdisciplinary perspectives. In particular, we would like to encourage submissions to the journal's "book, policy and initiative reviews"

Rhonda Phillips

rphillips@purdue.edu

1 Purdue University, West Lafayette, IN, USA

2 Seoul National University, Seoul, South Korea 
section that aims to be a space for reflection. See the invitation to submit reviews by Meg Holden in this journal's issue for more details.

We look forward to community well-being becoming a value and vision for our individual lives, communities, and societies around the globe.

Publisher's Note Springer Nature remains neutral with regard to jurisdictional claims in published maps and institutional affiliations. 